
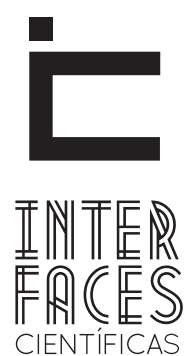

EDUCAÇÃO

ISSN IMPRESSO 2316-333X

ISSN ELETRÔNICO 2316-3828

DOI 10.17564/2316-3828.2015v3n3p43-54

\title{
ENTRE A TEORIA E A PRÁTICA: A PROVINHA BRASIL E O TRATAMENTO DA VARIAÇÃO LINGUISTICA NA ALFABETIZAÇÃO
}

Raquel MeisterKo Freitag ${ }^{1}$

\section{RESUMO}

Analisamos a articulação entre a teoria e a prática no que se refere ao tratamento da variação linguística na alfabetização, por meio da análise documental dos Parâmetros Curriculares Nacionais de Língua Portuguesa e da análise das questões que compõe a Provinha Brasil, instrumento de diagnóstico de avaliação da competência em leitura de alfabetizandos. Discutimos os pressupostos sociolinguísticos que orientam os Parâmetros Curriculares Nacionais de Língua Portuguesa, e que se manifestam nos conceitos de diversidade e de variedade, bem como na noção de competência comunicativa, presentes ao longo destes documentos e analisamos as questões do eixo de domínio do sistema alfabético da Provinha Brasil de 2010, a fim de identificamos os componentes sociolinguísticos. Constatamos que as contribuições de ordem teórico-práticas advindas da Sociolinguística que repercutem na formação dos professores de língua materna nas séries iniciais estão em dissonância com as diretrizes e com a prática, na medida que o tratamento da variação linguística está ausente na Provinha Brasil.

\section{PALAVRAS-CHAVE}

Competência Sociolinguística. Alfabetização. Parâmetros Curriculares Nacionais. Provinha Brasil. 


\section{ABSTRACT}

We analyze the theory and practice articulation to treatment of linguistic variation in initial literacy, with documental analysis of ParâmetrosCurricularesNacionais de Língua Portuguesa and questions of ProvinhaBrasil analysis. ProvinhaBrasil is a diagnostic instrument to measure reading skills from initial literacy. We discuss the ParâmetrosCurricularesNacionais de Língua Portuguesa based on sociolinguistics assumptions, as diversity, variety and communicative competence. Follow, we analyze the questions from ProvinhaBrasil that treat the alphabetical system domain to identifying the sociolinguistic devices. As results, we evidence that the theory/practice contributions from Sociolinguistics which are present in formation of first language teachers, especially from initial literacy, are in dissonance with practice and the directions, because the treatment of linguistic variations is absent in ProvinhaBrasil, the diagnostic instrument to measure reading skills.

\section{KEYWORDS}

Sociolinguistic Competence. Literacy. Parâmetros Curriculares Nacionais. Provinha Brasil.

\section{RESUMEN}

El objetivo del estudio es analizar la relación entre la teoría y la práctica en el tratamiento de la variación lingüística en materia de alfabetización, a través del análisis documental de los Parâmetros Curriculares Nacionais de Língua Portuguesa y el análisis de los temas que componen laProvinhaBrasil, herramienta de diagnóstico para la evaluación competencia lectora. Se discuten las bases sociolingüísticas que guían los Parâmetros Curriculares Nacionais de Língua Portuguesa, y que se manifiesta en los conceptos de diversidad y variedad, así como la noción de competencia comunicativa, presente en todos estos documentos, y analizar el eje del sistema alfabético de la Provinha
Brasil en 2010 para identificar los componentes sociolingüísticos. Observamos que las contribuciones teóricas y prácticas de la Sociolingüística que repercuten en la formación de los docentes de lengua materna en los primeros grados están en desacuerdo con las directrices y con la práctica, aunque el tratamiento de la variación lingüística está ausente en Provinha Brasil.

\section{PALABRAS CLAVE}

Competencia Sociolingüística. Alfabetización. Parâmetros Curriculares Nacionais. Provinha Brasil. 


\section{INTRODUÇ̃̃̃O}

O cenário atual da educação básica no Brasil vem sendo modelado por uma série de políticas públicas de estado que vem sistematicamente instituindo avaliações seletivas e diagnósticas de larga escala, como Provinha Brasil, Prova Brasil e Enem. Tais políticas educacionais são pautadas em diretrizes curriculares que, em muitos casos, não dialogam com as diretrizes da academia (universidades e centros de pesquisa e de formação docente) que forma os professores e produz o conhecimento que respalda a estruturação dos documentos norteadores, configurando uma tensa relação dissonante entre a teoria - os pressupostos apresentados pelos Parâmetros Curriculares Nacionais de Língua Portuguesa - e a prática - o modo como as habilidades são avaliadas pelos exames.

No âmbito do projeto Ler + Sergipe: leitura para o letramento e cidadania (Programa Observatório da Educação, edital 38/2010/CAPES/INEP), que tenta contribuir para o diagnóstico das causas do fracasso na aprendizagem inicial da leitura, com especial atenção à variação linguística do alfabetizando, elegemos como foco de análise a Provinha Brasil, um instrumento de diagnóstico do nível de alfabetização de alunos durante o primeiro ano de escolarização cujo objetivo é fornecer informações que viabilizem a intervenção do professor no processo, de modo que, ao término do segundo ano de escolarização, o aluno esteja alfabetizado.

As habilidades de leitura avaliadas no exame estão distribuídas em uma matriz de competências articulada em dois eixos: o domínio do sistema da escrita e o do domínio da leitura. Já há estudos dedicados ao segundo eixo, especialmente no que tange aos gêneros e suportes textuais (CRISTOFOLINI, 2011; 2012), ficando em segundo plano o domínio do sistema da escrita. Se o processo de alfabetização se resumisse à conversão unívoca de fonemas a grafemas, o trabalho do professor seria muito mais simples. Ocorre que as normas ortográficas não obedecem ao input ao qual a criança está exposta, à sua variedade linguística. 0 sucesso ou fracasso do aluno na Provinha Brasil tem relação direta com a variedade linguística do professor aplicador (já que se trata de um instrumento com comandos orais) e a sua relação com a norma.

A partir de análises da Provinha Brasil, seus resultados e sua concepção (ROSÁRIO, 2012; ALMEIDA e FREITAG, 2012; FREITAG, ALMEIDA, ROSÁRIO, 2013), identificamos um cenário preocupante: enquanto os documentos oficiais orientam a prática pedagógica para o tratamento da variedade e diversidade linguística, a Provinha Brasil faz uma "higienização linguística” em seu diagnóstico do nível de leitura, evitando e barrando em suas questões contextos de variação linguística. Isto nos leva a refletir sobre a importância do tratamento da variação nas séries iniciais.

Ao se pensar a questão da educação em língua materna, podemos vê-la como uma atividade, um trabalho entre educador - educando por meio do qual instrumentaliza o aluno para o exercício da cidadania, como preconizam os Parâmetros Curriculares Nacionais de Língua Portuguesa (BRASIL, 1998a, b). Diferentes campos teóricos dos estudos linguísticos vêm mostrando sua contribuição para o ensino de língua materna (que não significa, no Brasil, ensinar “língua portuguesa"), e dentre estes, destacamos as contribuições da Sociolinguística nesta empreitada, na medida em que, ao estudar as relações entre língua e sociedade, foca os conceitos de diversidade e variedade, os quais são de fundamental importância para possibilitar ao aluno que amplie sua competência sociocomunicativa e torne-se efetivamente cidadão.

Dando continuidade ao que vimos desenvolvendo no campo do ensino de língua materna (GORSKI e FREITAG, 2007; FREITAG, 2011; COAN e FREITAG, 2011), tecemos reflexões sobre a contribuição da So- 
ciolinguística para a educação, particularmente para as séries iniciais, foco do projeto. Para tanto, discutimos os pressupostos sociolinguísticos que orientam os Parâmetros Curriculares Nacionais de Língua Portuguesa, e que se manifestam nos conceitos de diversidade e de variedade, bem como na noção de competência comunicativa, presentes ao longo destes documentos.

Partimos do pressuposto de que o professor de língua materna não pode deixar de levar em conta a compreensão da língua enquanto entidade concreta, heterogênea, como tem postulado a Sociolinguística. Afinal, não se pode ensinar o português do Brasil para um falante nativo ignorando aquilo que ele já sabe - a sua língua materna -, nem ignorando a diversidade de usos que o cerca.

\section{A COMPETÊNCIA SOCIOLINGUÍSTICA}

As discussões em torno da política linguística, mais precisamente do eixo voltado para o ensino de língua materna, e dos direitos linguísticos, na perspectiva do direito do falante usar e ter respeitada as variedades de sua comunidade de fala leva-nos a buscar amadurecer a reflexão sobre as relações entre a variação linguística e o ensino de língua materna, focando como a política educacional vem absorvendo o resultado das pesquisas na área. Vejamos o que dizem os documentos oficiais.

Nos Parâmetros Curriculares Nacionais de Língua Portuguesa (BRASIL, 1998b)² para o terceiro e quarto

2. Os Parâmetros Curriculares Nacionais são documentos institucionais do Ministério da Educação com orientações, referenciais para a educação, pautados na transversalidade e com o objetivo de contribuir para a formação de cidadãos mais conscientes, críticos, autônomos e participativos. Os Parâmetros Curriculares Nacionais dão diretrizes sobre o que e como ensinar nas diversas áreas do conhecimento. Há muitas críticas aos Parâmetros Curriculares Nacionais, sobre o modo como foram elaborados, sobre a sua potencialidade e difusão, sua intenção, entre outras mais específicas de cada área do saber. Na área de Língua Portuguesa, há uma mistura de teorias que são, por definição, imiscíveis. Por outro lado, há um endeusamento dos Parâmetros Curriculares Nacionais, que, muitas vezes, são colocados equivocadamente como marco nos estudos linguísticos (na verdade, os Parâmetros Curriculares Nacionais de Língua Portuguesa são apenas decorrência dos estudos linguísticos). ciclo, os conteúdos contemplados dividem-se em: a) uso da língua oral e escrita, que incorpora práticas de escuta e de leitura e práticas de produção de textos orais e escritos; e b) reflexão sobre a língua e a linguagem, que incorpora práticas de análise linguística.

O ensino dos conteúdos de língua materna deve levar em conta a articulação entre uso e reflexão, de forma que sejam vistos como uma totalidade. A análise linguística (ou seja, a reflexão sobre a língua nos seus diferentes níveis: fonológico, morfológico, sintático, semântico-pragmático) não está desvinculada das habilidades de escuta/fala/leitura/escritura, pois o uso linguístico - que se dá por meio de textos e não de palavras ou frases isoladas - fornece material para observação de diferentes fenômenos linguísticos; a análise linguística, por sua vez, realimenta as práticas de uso. Em relação à linguagem, segundo os Parâmetros Curriculares Nacionais de Língua Portuguesa, a escola deve oferecer condições para que o aluno desenvolva seus conhecimentos, sabendo:
a) ler e escrever conforme seus propósitos e demandas sociais;
b) expressar-se adequadamente em situações de inte- ração oral diferentes daquelas próprias de seu univer- so imediato;
c) refletir sobre os fenômenos da linguagem, parti- cularmente os que tocam a questão da variedade lin- guística, combatendo a estigmatização, discriminação e preconceitos relativos ao uso da língua. (BRASIL, 1998b, p. 59).

Tais metas da escola estão alinhadas com os pressupostos da Sociolinguística; as duas primeiras - ler e escrever conforme seus propósitos e demandas sociais, bem como expressar-se adequadamente nas situações de interação oral diferentes daquelas próprias do seu universo particular - referem-se ao conceito de adequação. Estas metas são subjacentes a uma concepção de língua como sistema heterogêneo, ou melhor, língua dotada de heterogeneidade sistemática, na medida em que lidamos com a ideia de adequação. A terceira meta elencada foca especificamente a questão da diversidade linguística, com 
ênfase na reflexão, colocada como estratégia de combate ao preconceito, estigma e discriminação, que são, pois, conceitos advindos da Sociolinguística.

Assim, os Parâmetros Curriculares Nacionais de Língua Portuguesa preconizam as práticas sociais, ou seja, as situações reais de interação, como condição para que se dê o ensino da língua, já que esta funciona para as pessoas interagirem socialmente; uma concepção de língua heterogênea, historicamente situada, que está sujeita a variações e mudanças; um trabalho pedagógico que contemple, de maneira articulada, usos linguísticos (ouvir-falar, ler-escrever) e reflexão sobre a língua(gem); o uso da língua adequado aos propósitos comunicativos e demandas sociais; e o combate ao preconceito linguístico.

A variação social, também, carrega marcas identitárias e se manifesta nas diferentes normas: a norma culta é usada pelas pessoas mais diretamente relacionadas com a cultura escrita que é historicamente legitimada (pessoas com alto grau de escolarização), ao passo que as normas ou variedades não padrão são utilizadas por indivíduos não escolarizados ou pouco escolarizados.

As variedades, culta e não-padrão usualmente refletem as diferenças sociais dos falantes. A norma culta, vista por muitos como o "falar corretamente", é considerada uma via de ascensão social. Quem não domina a variedade padrão da língua é marginalizado, ridicularizado, enfim, excluído: em uma entrevista para emprego, na escola, no vestibular. Porém, o domínio e o uso da variedade culta ficam restritos a uma parte muito pequena da população brasileira, que, não por coincidência, é a detentora do poder político e econômico.

O fenômeno do rotacismo (a troca de /l/ por // nos encontros consonantais, como em chicrete, broco, pranta, ao invés de chiclete, bloco, planta) e do iotismo (a troca do // por /y/ em posição intervocálica, como em teiado, paia, cuié, ao invés de telhado, palha, colher) costumam ser associados a comunidades rurais e são estigmatizadas. Entretanto, trata-se de variantes linguísticas de milhares de brasileiros falantes das variedades não padrão, a "classe social desprestigiada, marginalizada, que não tem acesso à educação formal e aos bens culturais da elite", para quem a fonética da norma culta é como a de uma língua estrangeira (BAGNO, 2001, p. 42).

Casos desse tipo costumam provocar reações de preconceito linguístico, principalmente naquelas pessoas que se situam nos pontos mais altos na pirâmide social, ou seja, que pertencem a um nível socioeconômico mais alto e que dominam a variedade culta da língua. 0 preconceito linguístico se manifesta em comentários do tipo: "Fulano fala errado", "Fulano não sabe falar direito", "A fala de fulano é feia"... A isso se chama valor social das formas variantes. A fala (ou escrita) é avaliada ou julgada em função do status social dos indivíduos que a utilizam, e não pelas características linguísticas em si.

É, papel da escola, ensinar a "norma culta" da língua, que é a variedade de prestígio na sociedade. Entretanto, a variedade linguística que o aluno traz de casa nunca deve ser desconsiderada e tachada de "erro". Os professores devem considerar os diferentes níveis de conhecimento prévio que os alunos apresentam e promover a ampliação desses conhecimentos, criando situações comunicativas diferenciadas para que os alunos estendam gradativamente o conhecimento linguístico já adquirido (BORTONI-RICARDO, 2004). Muitas vezes as diferenças entre as variedades dos alunos e a variedade da escola são tão grandes que parece estarmos diante de duas línguas diferentes.

Como preconizam os Parâmetros Curriculares Nacionais de Língua Portuguesa, ensinar língua portuguesa - língua materna - é instrumentalizar o aluno para o exercício da cidadania. E a Sociolinguística desempenha significativo papel nesta empreitada, na medida em que traz os conceitos de diversidade e variedade, os quais permitem que o aluno amplie sua competência sociocomunicativa e torne-se cidadão. 
A proposta dos Parâmetros Curriculares Nacionais de Língua Portuguesa - de que o aluno amplie suas possibilidades de participação social no exercício da cidadania; de que leia, escreva e se expresse oralmente conforme as demandas sociais; de que reflita sobre os fenômenos da linguagem, combatendo preconceitos; de que desenvolva as competências: interativa, textual e gramatical - encontra ressonância no discernimento das diferentes concepções de língua, norma e gramática, com ênfase à concepção de língua como atividade social, de língua como sistema heterogêneo historicamente situado (em que as variantes linguísticas são carregadas de significado social), de gramática descritiva funcional, de norma como resultado de regras de comportamento de grupos sociais.

Levando esta discussão para a realidade da sala de aula, é pertinente questionarmos em que momento tais conteúdos começam a ser trabalhados nas aulas de língua materna. Partindo da premissa de que a leitura é requisito para o exercício da cidadania, é natural que o desenvolvimento da competência sociocomunicativa enquanto disciplina curricular comece na alfabetização. Vejamos, então, o que dizem os Parâmetros Curriculares Nacionais para o primeiro e segundo ciclos (BRASIL, 1998a).

O documento inicia, reiterando a pluralidade teórica que o caracteriza, destacando as contribuições inclusive da Sociolinguística (BRASIL, 1998a, p. 20). Tal alinhamento fica evidente quando, no documento, é explicitada a questão da variedade que a escola deve ensinar:

A Língua Portuguesa, no Brasil, possui muitas variedades dialetais. Identificam-se geográfica e socialmente as pessoas pela forma como falam. Mas há muitos preconceitos decorrentes do valor social relativo que é atribuído aos diferentes modos de falar: é muito comum se considerarem as variedades linguísticas de menor prestígio como inferiores ou erradas. (BRASIL, 1998a, p. 27).

O foco no ensino voltado à diversidade e variedade perpassa todo o ensino fundamental, iniciando-se já na alfabetização, de modo que o aluno saiba "utilizar diferentes registros, inclusive os mais formais da variedade linguística valorizada socialmente, sabendo adequá-los às circunstâncias da situação comunicativa de que participam; conhecer e respeitar as diferentes variedades linguísticas do português falado" (BRASIL, 1998a, p. 33).

O foco das orientações do documento recai para a alfabetização, envolvendo dois processos: a compreensão do sistema de escrita da língua - os aspectos notacionais - e o funcionamento da linguagem que se usa para escrever - os aspectos discursivos. A questão da variação perpassa tanto o sistema quanto o uso, pois envolve "situações em que se busca a adequação da fala ou da escrita própria e alheia, a avaliação sobre a eficácia ou adequação de certas expressões no uso oral ou escrito, os comentários sobre formas de falar ou escrever [...] etc." (BRASIL, 1998a, p. 54).

O documento faz crítica ao modelo de ensino de ortografia baseado na repetição e correção: a bagagem sociolinguística é subjacente: "a análise e a reflexão sobre o sistema alfabético de escrita e a correspondência fonográfica. São atividades que exigem uma atenção à análise - tanto quantitativa como qualitativa - da correspondência entre segmentos falados e escritos" (BRASIL, 1998a, p. 50).

Entretanto, ao apresentar orientações para o ensino de regras produtivas e reprodutivas, itens frequentes e infrequentes, a questão da variação começa a ser travada nos Parâmetros Curriculares Nacionais de Língua Portuguesa para o primeiro e segundo ciclos, na medida em que as regras exemplificadas tratam apenas de contextos ortográficos categóricos, que são uniformes no português, como as regras biunívocas (relação direta entre grafema e fonema, como no caso de F, V; G, etc.), contextuais (não há relação direta, mas o contexto prevê quais são as formas, como, por exemplo, o uso de RR, QU, GU, NH, M/N antes de consoante etc.) e as regras morfológicas (a escolha da forma ortográfica depende da classe morfológica 
da palavra, como os adjetivos terminados em /eza/ rique(z)a, pobre(z)a).

Não há nenhuma menção às regras variáveis, dependentes da variedade sociolinguística do alfabetizando, como a realização do $\mathrm{R}$ e do $\mathrm{S}$ em final de sílaba, que pode ter diferentes formas, a depender da região, menos ainda aos contextos vocálicos, que são amplamente variáveis no português (alçamento e harmonização, por exemplo). Como explicar que escrevemos "bolo", mas falamos, na maior parte das variedades do português, /bolu/? Tais perspectivas não fazem parte das orientações dos Parâmetros Curriculares Nacionas de Língua Portuguesa para o primeiro e segundo ciclos, que, ao contrário do que é previsto para os oito anos do ensino fundamental e que é amplamente tratado nos terceiro e quarto ciclos, promove uma higienização da variação linguística na alfabetização. Vejamos como isso se dá na prática, na Provinha Brasil. Primeiramente, passemos à descrição do instrumento de avaliação.

\section{A PROVINHA BRASIL}

A Provinha Brasil é uma avaliação diagnóstica do nível de alfabetização das crianças matriculadas no segundo ano de escolarização das escolas públicas brasileiras. Essa avaliação acontece em duas etapas, uma no início e a outra ao término do ano letivo. A aplicação em períodos distintos possibilita aos professores e gestores educacionais a realização de um diagnóstico mais preciso que permite conhecer o que foi agregado na aprendizagem das crianças, em termos de habilidades de leitura dentro do período avaliado.

A partir dos seus resultados, os gestores e professores têm condições de intervir de forma mais eficaz no processo de alfabetização, aumentando as chances de que todas as crianças, até os oito anos de idade, saibam ler e escrever, conforme uma das metas previstas pelo Plano de Metas Compromisso Todos pela Educação (BRASIL, 2007).
É importante destacarmos que a Provinha Brasil não é exame de "aferimento de qualidade"; conforme o Plano de Metas Compromisso Todos pela Educação, em seu $3^{\circ}$ :

\begin{abstract}
A qualidade da educação básica será aferida, objetivamente, com base no IDEB, calculado e divulgado periodicamente pelo INEP, a partir dos dados sobre rendimento escolar, combinados com o desempenho dos alunos, constantes do censo escolar e do Sistema de Avaliação da Educação Básica - SAEB, composto pela Avaliação Nacional da Educação Básica - ANEB e a Avaliação Nacional do Rendimento Escolar (Prova Brasil). (BRASIL, 2007, p. 3).
\end{abstract}

A Provinha Brasil é elaborada pelo INEP, e distribuída pelo Ministério da Educação (MEC)/Fundo Nacional de Desenvolvimento da Educação (FNDE) para as secretarias de educação municipais, estaduais e do Distrito Federal. Assim, todos os anos os alunos da rede pública de ensino, matriculados no segundo ano de escolarização, têm oportunidade de participar do ciclo de avaliação da Provinha Brasil, pois o exame visa oferecer informações que viabilizem a intervenção, quando ainda há tempo para melhorar o ensino, de forma que, ao término do segundo ano de escolarização, as crianças estejam alfabetizadas.

Trata-se de uma avaliação aplicada pelas próprias escolas, avaliando internamente o desempenho de seus alunos da série/ano que já concluíram um ano de escolarização (nas escolas cujo Ensino Fundamental tem nove anos, fazem o teste as crianças do $2^{\circ}$ ano; nas escolas em que o Ensino Fundamental tem duração de oito anos, os estudantes deverão fazer o teste na $2^{\mathrm{a}}$ série).

As habilidades avaliadas pela Provinha Brasil se dividem em dois grandes eixos: a) domínio do sistema de escrita e b) domínio da leitura, conforme Quadro 1. 0 primeiro eixo refere-se à aprendizagem do sistema alfabético de escrita, averiguando se o alfabetizando compreende a lógica do seu funcionamento, identificando as letras do alfabeto e suas 
diferentes formas de apresentação gráfica, reconhecendo as unidades sonoras como fonemas e sílabas e suas representações gráficas, reconhecen- do as diferentes estruturas silábicas das palavras e conhecendo as marcas gráficas que demarcam o início e o término de cada palavra escrita.

Quadro 1 - Matriz de Referência

\begin{tabular}{|c|c|}
\hline $1^{\circ} \mathrm{EIXO}$ & $\begin{array}{l}\text { Apropriação do sistema de escrita: habilidades relacionadas à identificação e ao } \\
\text { reconhecimento de princípios do sistema de escrita. }\end{array}$ \\
\hline Habilidade (descritor) & Detalhamento da habilidade (descritor) \\
\hline D1: Reconhecer letras & $\begin{array}{l}\text { Diferenciar letras de outros sinais gráficos, identificar pelo nome as letras do } \\
\text { alfabeto ou reconhecer os diferentes tipos de grafia das letras. }\end{array}$ \\
\hline D2: Reconhecer sílabas & $\begin{array}{l}\text { Identificar o número de sílabas que formam uma palavra por contagem ou } \\
\text { comparação das sílabas de palavras dadas por imagens. }\end{array}$ \\
\hline $\begin{array}{l}\text { D3: Estabelecer relação } \\
\text { entre unidades sonoras } \\
\text { e suas representações } \\
\text { gráficas. }\end{array}$ & \begin{tabular}{|rl} 
Identificar em palavras a representação de unidades sonoras como: \\
$\square$ & letras que possuem correspondência sonora única (ex.: p, b, t, d, f); \\
$\square$ & letras com mais de uma correspondência sonora ( ex.: "c"e "g"); \\
$\square$ & sílabas.
\end{tabular} \\
\hline $2^{\circ} \mathrm{EIXO}$ & Leitura \\
\hline Habilidade (descritor) & Detalhamento da habilidade (descritor) \\
\hline D4: Ler palavras. & $\begin{array}{l}\text { Identificar a escrita de uma palavra ditada ou ilustrada, sem que isso seja } \\
\text { possível a partir do reconhecimento de um único fonema ou de uma única sílaba. }\end{array}$ \\
\hline D5: Ler frases & $\begin{array}{l}\text { Localizar informações em enunciados curtos e de sentido completo, sem que } \\
\text { isso seja possível a partir da estratégia de identificação de uma única palavra } \\
\text { que liga o gabarito à frase. }\end{array}$ \\
\hline $\begin{array}{l}\text { D6: Localizar informação } \\
\text { explícita em textos. }\end{array}$ & $\begin{array}{l}\text { Localizar informação em diferentes gêneros textuais, com diferentes tamanhos } \\
\text { e estruturas e com distintos graus de evidência da informação, exigindo, em } \\
\text { alguns casos, relaciona dados do texto para chegar à resposta correta. }\end{array}$ \\
\hline $\begin{array}{l}\text { D7: Reconhecer assunto de } \\
\text { um texto. }\end{array}$ & $\begin{array}{l}\text { Antecipar o assunto do texto com base no suporte ou nas características gráficas } \\
\text { do gênero ou, ainda, em um nível mais complexo, reconhecer o assunto, } \\
\text { fundamentando-se apenas na leitura individual do texto. }\end{array}$ \\
\hline $\begin{array}{l}\text { D8: Identificar a finalidade do } \\
\text { texto. }\end{array}$ & $\begin{array}{l}\text { Antecipar a finalidade do texto com base no suporte ou nas características } \\
\text { gráficas do gênero ou, ainda, em um nível mais complexo, identificar a finalidade, } \\
\text { apoiando-se apenas na leitura individual do texto. }\end{array}$ \\
\hline $\begin{array}{l}\text { D9: Estabelecer relação } \\
\text { entre partes do texto. }\end{array}$ & $\begin{array}{l}\text { Identificar repetições e substituições que contribuem para a coerência e } \\
\text { a coesão textual. }\end{array}$ \\
\hline D 10: Inferir informação & Inferir informação. \\
\hline
\end{tabular}

Fonte: Brasil (2011, p. 10-11). 
O segundo eixo busca aferir as habilidades de ler palavras, localizar informações explícitas em frases ou textos, realizar inferências, reconhecer o assunto de um texto, suas finalidades e estabelecer relações entre suas partes.

É importante destacar que a matriz de competência da Provinha Brasil não contempla todas as habilidades relativas aos processos de alfabetização e letramento (BRASIL, 2011); Almeida (2012) destaca que o caráter limitado das habilidades contempladas pela matriz de referência da Provinha Brasil, que se restringem ao modelo autônomo de letramento medido por meio de questões de múltipla escolha, não abrange o todo complexo de habilidades que compõem a caracterização de gêneros textuais como as narrativas, por exem$\mathrm{plo}^{3}$. É possível que o mesmo se dê no plano do tratamento da variação, objeto específico deste trabalho.

O teste é constituído por 24 itens de múltipla escotha, lidos total, parcialmente ou não lidos pelo professor/aplicador. São aplicados dois testes: um no início do ano e outro ao final. A aplicação e correção podem ser feitas por pessoa externa ou pelo próprio professor, utilizando uma planilha de marcação de gabaritos, pela qual se obtém o número de acertos por aluno e a média de acertos da turma. 0 número ou a média de acertos devem ser relacionados aos níveis de desempenho, conforme o Quadro 2.

3. A Provinha Brasil tem suscitado discussões quanto às contribuições "para a formulação de políticas públicas e quanto ao modo de conceber a alfabetização e práticas dessa natureza adotadas e analise de prova, visando à formação continuada de alfabetizadores" (Morais ET AL., 2009, p. 302; Gontijo, 2012). Esteban (2009, p. 47) tece críticas a respeito dessa avaliação, que acredita reduzir o processo de alfabetização, ignorando-o como uma prática sociocultural e julga a Provinha Brasil "predominantemente quantitativa e classificatória, além de questionar a capacidade desse processo de avaliação oferecer contribuições efetivas para a alfabetização de todas as crianças”. Também tem se pesquisado a relação entre o que se ensina durante o ano letivo em língua portuguesa e o que é aplicado no teste da Provinha Brasil: Moraes (2012) e Rosário (2012) correlacionam o conteúdo cobrado na Provinha Brasil com o conteúdo dos cursos de formação de professores alfabetizadores, constatando dissonância entre as práticas.
Quadro 2 - Níveis de desempenho

\begin{tabular}{|c|c|}
\hline $\begin{array}{l}\text { Nível } 1 \\
\text { Até } 13 \\
\text { acertos }\end{array}$ & $\begin{array}{l}\text { Início da apropriação das habilidades } \\
\text { referentes ao domínio do sistema alfa- } \\
\text { bético. }\end{array}$ \\
\hline $\begin{array}{l}\text { Nível } 2 \\
\text { De } 14 \text { a } 17 \\
\text { acertos }\end{array}$ & $\begin{array}{l}\text { Consolidação das habilidades referen- } \\
\text { tes ao conhecimento e uso do sistema } \\
\text { de escrita, já associam adequadamen- } \\
\text { te letras e sons, iniciando a leitura de } \\
\text { palavras com vários tipos de estrutura } \\
\text { silábica. }\end{array}$ \\
\hline $\begin{array}{l}\text { Nível } 3 \\
\text { De } 18 \text { a } 20 \\
\text { acertos }\end{array}$ & $\begin{array}{l}\text { Consolidação da capacidade de ler pala- } \\
\text { vras de diferentes tamanhos e padrões } \\
\text { silábicos, frases com sintaxe simples } \\
\text { (sujeito + verbo + objeto) e utilização de } \\
\text { estratégias para ler, superficialmente, } \\
\text { textos curtos. }\end{array}$ \\
\hline $\begin{array}{l}\text { Nível } 4 \\
\text { De } 21 \text { a } 22 \\
\text { acertos }\end{array}$ & $\begin{array}{l}\text { Leitura de textos na ordem direta (iní- } \\
\text { cio, meio e fim), de estrutura sintática } \\
\text { simples (sujeito+verbo+objeto) e de } \\
\text { vocabulário explorado comumente na } \\
\text { escola. Localização de informações, in- } \\
\text { ferências e compreensão do assunto do } \\
\text { texto. }\end{array}$ \\
\hline $\begin{array}{l}\text { Nível } 5 \\
\text { De } 23 \text { a } 24 \\
\text { acertos }\end{array}$ & $\begin{array}{l}\text { Domínio do sistema de escrita e da lei- } \\
\text { tura compreensiva, acima do definido } \\
\text { como aceitável para o fim do segundo } \\
\text { ano de escolarização. }\end{array}$ \\
\hline
\end{tabular}

Fonte: Brasil (2011, p. 14).

Apresentado o perfil da Provinha Brasil, na seção a seguir tecemos considerações acerca do espaço destinado ao tratamento da variação linguística neste instrumento, de acordo com o que preconizam os Parâmetros Curriculares Nacionais. Intentamos verificar a aderência entre as diretrizes apregoadas pelos documentos e a prática - na forma das questões da Provinha Brasil. 


\section{A PROVINHA BRASIL E A COMPETÊNCIA SOCIOLINGUÍSTICA}

Se o processo de alfabetização se resumisse à conversão unívoca de fonemas a grafemas, o trabalho do professor seria muito mais simples. Ocorre que as normas ortográficas não obedecem ao input ao qual a criança está exposta, à sua variedade linguística. 0 sucesso ou fracasso do aluno na Provinha Brasil tem relação direta com a variedade linguística do professor aplicador (já que se trata de um instrumento, também, com comandos orais) e a sua relação com a variedade linguística do alfabetizando, pois, como vimos anteriormente, o não reconhecimento e o despreparo do professor para lidar com a variação influi no fracasso escolar.

Figura 1 - Questão exemplo da Provinha Brasil 2010

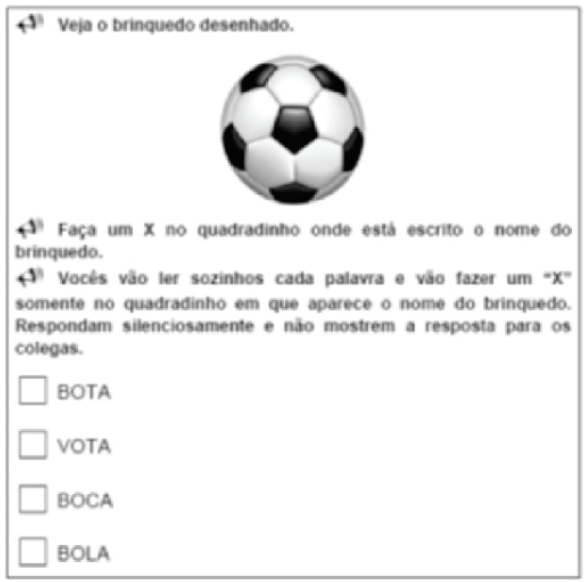

Fonte: BRASIL, Provinha Brasil 2010.
A análise da matriz de competências da Provinha Brasil aponta que a variação linguística não faz parte das habilidades avaliadas por este instrumento. No primeiro eixo, domínio do sistema de escrita, o descritor D3, que avalia a capacidade de o alfabetizando estabelecer relação entre unidades sonoras e suas representações gráficas, aponta como detalhamento da habilidade e exemplificação apenas contextos cuja correspondência grafofonêmica é unívoca: "letras que possuem correspondência sonora única (ex.: p, b, t, d, f)"; ou contextos cuja correspondência grafofonêmica não é unívoca "letras com mais de uma correspondência sonora (ex.: "c" e “g”)", mas não se encontra em situação de variação diatópica no território brasileiro, diferentemente, por exemplo, dos casos de rotacismo e iotismo (respectivamente, a troca do "r" pelo "l" e a troca do "lh" pelo "i" na fala, e por, conseguinte, na escrita inicial) (FREITAG, 2010; ARAUJO ET AL., 2010).

Figura 2 - Questão 10 da Provinha Brasil 2010, teste 2

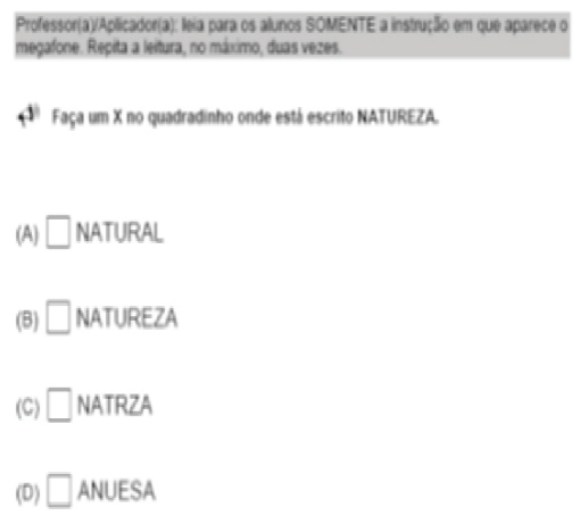

Fonte: BRASIL, Provinha Brasil 2010. 
Figura 3 - Questão 2 da Provinha Brasil 2010, teste 1

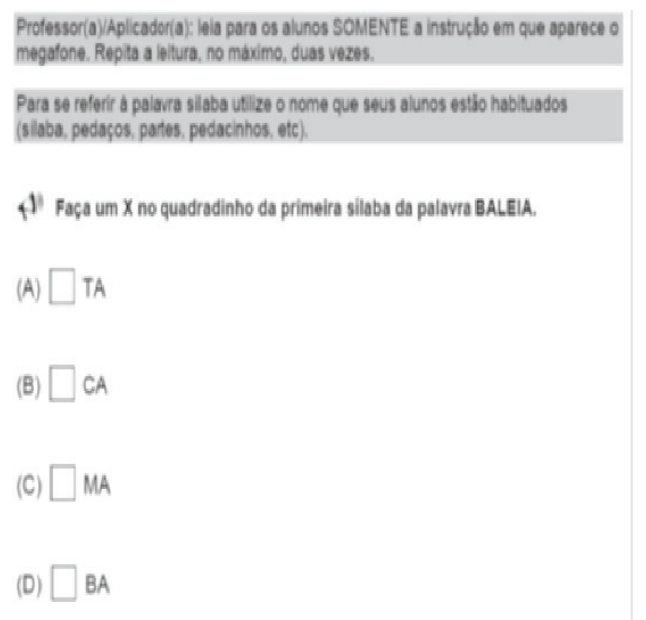

Fonte: BRASIL, Provinha Brasil 2010.

Se as diretrizes da matriz de competência barram a variação, obviamente o instrumento também a barrará. Observemos a questão exemplo do instrumento de avaliação, na Figura 1. O megafone antes da frase significa que esta deve ser lida pelo aplicador do teste. Em qualquer variedade do português, "bola” terá a mesma realização fonêmica: /bla/.Não há espaço para uma forma alternante, para a realização alofônica, pois estes segmentos, no português, não são alofônicos. Talvez se trate de uma escolha cuidadosa para a questão exemplo; porém, ao observarmos as demais questões, vemos que o padrão se repete, com a cuidadosa recorrência de contextos que travam a possibilidade de variação.

Observamos, nas Figuras 2-4, a repetição do padrão, com a recorrência de contextos de univocidade, tanto por parte da leitura do professor, quanto por parte do aluno e sua representação mental da palavra. Na perspectiva da Fonologia de Usos (BYBEE, 2001), o uso da língua modela a forma e o conteúdo dos sistemas de sons. Assim, a frequência com que
Figura 4 - Questão 17 da Provinha Brasil 2010, teste 1

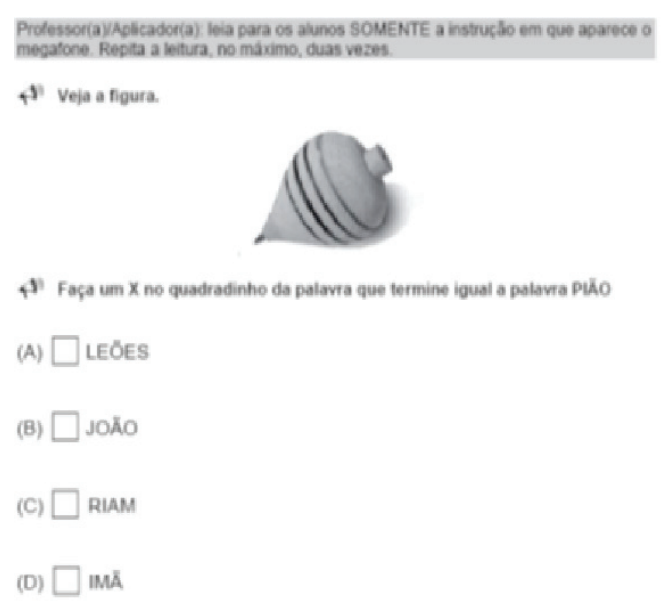

dada palavra ou sequência de palavras é usada e a frequência com que certos padrões recorrem em uma língua afetam a natureza da representação mental e, em alguns casos, o corpo fonético das palavras. 0 uso compreende não só o processamento da língua, mas os usos sociais e interacionais da língua (BYBEE, 2001, p. 2) - correlação com a Sociolinguística, com a produtividade das variantes em dados contextos e a marcação social a qual as formas estão sujeitas.

A "higienização" da variação na Provinha Brasil aparentemente vai de encontro ao que preconizam os Parâmetros Curriculares Nacionais de Língua Portuguesa, que fazem da variedade e diversidade os esteios do ensino de língua. Seria um caso de dissonância entre as diretrizes e a prática? Ou teríamos questões mais profundas subjacentes à higienização da variação linguística na Provinha Brasil, tais como: Qual é a idade do amadurecimento da competência sociolinguística e, por conseguinte, a sua inclusão nos programas de ensino de língua materna? 
Assumimos a premissa de que, por a língua ser uma atividade social, ao nascer o indivíduo já está em processo de aprendizagem, não havendo, portanto, motivação para a exclusão do tratamento da variação na alfabetização. Até que ponto é produtivo minimizar efeitos da variedade linguística se a Provinha Brasil não é instrumento de ranqueamento? Apesar de ser um instrumento de diagnóstico, a Provinha Brasil tem sido interpretada equivocadamente como um instrumento de avaliação (ranqueando alunos, escolas e professores), ou então tem sido menosprezada por focar a competência de leitura do estudante (as questões do instrumento são objetivas).

Como vimos, as habilidades de leitura avaliadas estão distribuídas em uma matriz de competências articulada em dois eixos: o domínio do sistema da escrita e o do domínio da leitura. Trata-se de campo de estudos fértil e necessário para aprimorar ainda mais o instrumento, tarefa com a qual pretendemos contribuir com o desenvolvimento do o projeto Ler + Sergipe: Leitura para o letramento e a cidadania foca especialmente a variedade linguística do aluno e sua relação com o processo de alfabetização.

\section{CONSIDERAÇÕES FINAIS}

Os Parâmetros Curriculares Nacionais de Língua Portuguesa preconizam as práticas sociais, ou seja, as situações reais de interação, como condição para que se dê o ensino de língua; uma concepção de língua heterogênea; um trabalho pedagógico que contemple usos linguísticos e reflexão sobre a língua; o uso da língua adequado aos propósitos comunicativos e demandas sociais; e o combate ao preconceito linguístico. Porém, constatamos que as contribuições de ordem teórico-práticas advindas da Sociolinguística que repercutem na formação dos professores de língua materna, focando especialmente os professores das séries iniciais, estão em dissonância com as diretrizes e a prática, na medida que o tratamento da variação linguística está ausente no instrumento de diagnóstico da competência em leitura, a Provinha Brasil.

Qual é a idade do amadurecimento da competência sociolinguística e, por conseguinte, a sua inclusão nos programas de ensino de língua materna? Até que ponto é produtivo minimizar efeitos da variedade linguística se a Provinha Brasil não é instrumento de ranqueamento? Responder a tais questões se faz necessário para o aprimoramento da Provinha Brasil e para seu objetivo fundamental: auxiliar os gestores e professores a intervir de forma mais eficaz no processo de alfabetização, aumentando as chances de que todas as crianças, até os oito anos de idade, saibam ler e escrever, conforme uma das metas previstas pelo Plano de Metas Compromisso Todos pela Educação (BRASIL, 2007).

\section{REFERÊNCIAS}

\section{ALMEIDA, A. N. S. A competência narrativa na pro-}

vinha Brasil: um estudo do desempenho dos estudantes da EMEF Tenisson Ribeiro - Aracaju/SE. São Cristróvão, SE. 2012. 127f. Dissertação (Mestrado em Letras) - Universidade Federal de Sergipe, 2012.

ALMEIDA, A. N.; FREITAG, R. M. K. Análise do diagnóstico do desempenho em leitura: Provinha Brasil vs. fluência em leitura oral. Signo, n.37, v.63, 2012. p.98110. Disponível em: <http://online.unisc.br/seer/index.php/signo/article/viewFile/2967/2325>. Acesso em: 10 de janeiro de 2014

ARAUJO, A. S.; BARRETO, E. A.; CARVALHO, E. S. S.; FREITAG, R. M. K. Vamos prantar frores no grobo da terra: estudando o rotacismo nas séries iniciais da rede municipal de ensino de Moita Bonita/SE. RevLet - Revista Virtual de Letras, n.2, v.1, 2010. p.1731. Disponível em: <http://www.revlet.com.br/artigos/50.pdf>. Acesso em: 10 de janeiro de 2014 
BAGNO, M. Preconceito linguístico - o que é, como se faz. 15.ed. São Paulo: Loyola, 2010.

BORTONI-RICARDO, S. M. Educação em língua materna: a sociolinguística na sala de aula. São Paulo: Parábola, 2004.

BRASIL. Casa Civil. Plano de metas compromisso todos pela educação. Decreto n 6.094, de 24 de abril de 2007.

BRASIL. Ministério da Educação e do Desporto. Instituto de Pesquisas Educacionais Anísio Freire. Provinha Brasil: guia de aplicação, teste 1. Brasília: MEC/ INEP, 2011, 36 p.

BRASIL. Ministério da Educação e do Desporto. Secretaria de Educação Fundamental. Parâmetros curriculares nacionais primeiro e segundo ciclos do ensino fundamental: Introdução aos parâmetros curriculares nacionais. Brasília: MEC/SEF, 1998a, 87p.

BRASIL. Ministério da Educação e do Desporto. Secretaria de Educação Fundamental. Parâmetros curriculares nacionais terceiro e quarto ciclos do ensino fundamental: Introdução aos parâmetros curriculares nacionais. Brasília: MEC/SEF, 1998b. 104p.

BYBEE, Joan. Phonology and language use. Cambridge: Cambridge University Press, 2001.

COAN, M; FREITAG, R. M. K. Sociolinguística variacionista: pressupostos teórico-metodológicos e propostas de ensino. Domínios de Lingu@gem, n.4, v.2, 2010. p.173-194. Disponível em: <http://www. seer.ufu.br/index.php/dominiosdelinguagem/article/ view/11618/6863>. Acesso em: 10 de janeiro de 2014

CRISTOFOLINI, C. Refletindo sobre a Provinha Brasil a partir das dimensões sociocultural, linguística e cognitiva da leitura. Alfa: Revista de Linguística, n.56, v.1, 2012. p.217-247. Disponível em: <http://dx.doi. org/10.1590/S1981-57942012000100010>. Acesso em: 10 de janeiro de 2014
CRISTOFOLINI, C. Algumas considerações a respeito do letramento na Provinha Brasil. WorkingPapers em Linguística, n.11, v.2, 2011. p.25-35. <http://dx.doi. org/10.5007/1984-8420.2010v11n2p25>. Acesso em: 10 de janeiro de 2014

FREITAG, R. M. K. Implicações da variação na alfabetização: a lateral palatal e seus correspondentes grafêmicos. Leitura, n.46, v.1, 2011. p.37-56. Disponível em: <http://www.seer.ufal.br/index.php/revistaleitura/article/viewArticle/312>. Acesso em: 10 de janeiro de 2014

FREITAG, R. M. K. Entre norma e uso, fala e escrita: contribuições da Sociolinguística à alfabetização. Nucleus, n.8, v.1, 2010. p.1-10. Disponível em: <http:// dx.doi.org/10.3738/1982.2278.542>. Acesso em: 10 de janeiro de 2014

FREITAG, R. M. K.; ALMEIDA, A. N. S.; ROSARIO, M. M. S. Contribuições para o aprimoramento da Provinha Brasil enquanto instrumento diagnóstico do nível de alfabetização e letramento nas séries iniciais.Rev. Bras. Estud. Pedagog.,v.94, n. 237, 2013. p.390-416. Disponível em: <http://dx.doi.org/10.1590/S2176$66812013000200004>$. Acesso em: 10 de janeiro de 2014

GONTIJO, C. Avaliação da alfabetização: Provinha Brasil. Educação e Pesquisa, n.38, v.3, 2012. p. 603-622. Disponível em: <http://dx.doi.org/10.1590/S151797022012000300005>. Acesso em: 10 de janeiro de 2014

GORSKI, E. M., FREITAG, R. M. K. Língua materna e ensino: alguns pressupostos para a prática pedagógica. In: C. R. SILVA. (org). Ensino de português: demandas teóricas e práticas. João Pessoa: Ideia, 2007. p.91125.

MORAIS, A. G. Políticas de avaliação da alfabetização: discutindo a Provinha Brasil. Rev. Bras. Educ., n.17, v.51, 2012. p.551-572. Disponível em: <http:// 
dx.doi.org/10.1590/S1413-24782012000300004>.

Acesso em: 10 de janeiro de 2014

MORAIS, A.G.; LEAL, T. F.; ALBUQUERQUE, E.B.C. "Provinha Brasil": monitoramento da aprendizagem e formulação de políticas educacionais. RBPAE, n.25, v.2, 2009. p.301-320. Disponível em: <http://seer.ufrgs.br/rbpae/article/view/19499>. Acesso em: 10 de janeiro de 2014

ROSÁRIO, M. M. S. Avaliação de políticas públicas para a alfabetização: formação do professor alfabetizador, concepção e aplicação da Provinha Brasil. 2012. Dissertação (Mestrado em Letras) - Universidade Federal de Sergipe, 2012.

1. Docente da Universidade Estadual do Paraná- UNESPAR/FAFIPA. Doutoranda em Educação pelo Programa de Pós-Graduação em Educação da Universidade Estadual de Maringá. Especialista em Educação Especial. Graduada em Pedagogia pela Universidade Estadual de Maringá. Atua também na modalidade de Educação a Distância e na supervisão do Pacto Nacional pela Alfabetização da Idade Certa (MEC), ambos realizados na Universidade Estadual de MaringáUEM. Pesquisadora do grupo de pesquisa: Desenvolvimento, aprendizagem e educação. Com ênfase no Desenvolvimento e aprendizagem e Necessidades educacionais especiais. E-mail: aline tacon@hotmail.com

2. Professora Titular do Departamento de Teoria e Prática da Educação da Universidade Estadual de Maringá, atuando no curso de graduação em pedagogia e no mestrado e doutorado em educação (PPE). Diretora do Centro de Ciências Humanas, Letras e Artes (CCH). É doutora em Psicologia Escolar e do Desenvolvimento Humano pela Universidade de São Paulo e realizou estágio pós-doutoral pela Universidade Federal de São Carlos. E-mail: nnrmori@uem.br 